\title{
RADIKALISME ISLAM DALAM BINGKAI KEINDONESIAAN
}

Oleh: Yosep Aurelius Woi Bule

\begin{abstract}
Abstrak:
Fenomena radikalisme Islam telah menjadi wacana publik yang sangat mencemaskan, sebab model radikalisme Islam ini sangat identitk dengan kekerasan dan terorisme. Artikel ini mengulas radikalisme Islam sebagai sebuah fenomena global dalam bingkai keindonesiaan, yang memiliki penduduk Muslim terbanyak serta hidup dalam keberagaman. Melalui berbagai kajian kepustakaan serta temuan hasil riset, penulis mengangkat fakta radikalisme Islam yang termanifestasi dalam gerakangerakan islamisme, baik dalam konteks global maupun dalam konteks Indonesia. Tujuan utamanya adalah untuk memahami sejauh mana kiprah radikalisme Islam di Indonesia berimplikasi pada sistem berdemokrasi dan konteks pluralisme di Indonesia. Akhir dari uraian ini memuat catatan kritis terhadap radikalisme Islam di Indonesia untuk mengembalikan citra Islam yang rahmatan lil alamin (rahmat untuk alam semesta).
\end{abstract}

Kata-kata Kunci: radikalisme, intoleransi, demokrasi, pluralisme

\section{Pengantar}

$\mathrm{H}$

orace M. Kallen mencirikan radikalisme dalam tiga kecenderungan berikut: pertama, radikalisme merupakan respons terhadap kondisi yang sedang berlangsung dalam bentuk evaluasi, penolakan atau perlawanan. Kedua, radikalisme tidak berhenti pada upaya penolakan, melainkan berupaya menggantikan tatanan tersebut dengan suatu bentuk tatanan yang lain. Ketiga, kuatnya keyakinan kaum radikalis akan ideologi yang mau diterapkan tersebut. ${ }^{1}$ Berdasarkan ketiga kecenderungan yang menjadi ciri radikalisme tersebut, maka radikalisme dalam Islam dapat diasosiasikan dengan gerakan-gerakan dalam Islam yang menolak model keberagamaan konservatif serta tatanan sosial-politik yang modern-sekular dan berusaha menggantikannya dengan ajaran dan sistim politik islamis dalam semua segi kehidupan.

Untuk merealisir ambisi tersebut maka tekanan pada politik sangat kuat dengan konsep bahwa negara Islam merupakan salah satu agenda yang harus diperjuangkan dalam rangka mewujudkan kehidupan yang islami. Tekanan dan pijakan ada pada politik karena memang gerakan radikalisme Islam berpandangan bahwa agama dan politik tidak dapat dipisahkan. Dalam format yang demikian, Islam merupakan tipikal sosial-politik, di mana fungsi agama dan politik tidak dapat dipisahkan melainkan harus terbentuk secara formalistik-legalistik, yang disebut negara Islam. ${ }^{2}$

Indonesia adalah negara yang menganut sistem demokrasi Pancasila dengan jumlah penduduk Muslim terbanyak. Berdasarkan fakta ini, di satu sisi, Indonesia

${ }^{1}$ Horace M. Kallen, "Radicalism", dalam Edwin R.A. Seligman, Encyclopedia of the Social Sacience, Vol. XIII-XIV (New York: The Macmillan Company, 1972), 51-54.

2 Abdurahman dan kawan-kawan, Al-Qur'an dan Isu-Isu Kontemporer (Yogyakarta: Elsaq Press, 2011), 58. 
merupakan negara yang berhasil menuju transisi demokrasi dalam masyarakat mayoritas Muslim; di sisi lain, Indonesia dapat menjadi contoh bagi bangkitnya kekerasan agama dan intoleransi dalam demokrasi, khususnya karena maraknya aktivitas organisasi massa yang main hakim sendiri dan memakai agama untuk membenarkan eksistensi kelompok ormas tersebut. ${ }^{3}$ Dengan menggunakan kajian pustaka serta studi riset, tulisan ini mencoba membedah radikalisme Islam melalui gerakan islamisme dalam konteks global serta dampaknya bagi ruang kebhinekaan Indonesia. Fakta adanya radikalisme Islam menjadi bagian awal dari uraian ini, selanjutnya dengan mencermati model radikalisme Islam melalui gerakan islamisme di Indonesia, penulis ingin mengkaji apakah islamisme di Indonesia mengancam demokrasi Pancasila dan keberagaman budaya di Indonesia. Tulisan ini kemudian berakhir dengan kritik terhadap islamisme sebagai sebuah bentuk radikalisme Islam demi menuju humanisme Islam yang modernis dan menjunjung tinggi pluralitas.

\section{Fakta Adanya Radikalisme Islam}

\section{a. Gerakan Global}

Radikalisme Islam adalah isu yang menjadi wacana publik pasca serangan 11 september 2001, atau dikenal dengan serangan " $9 / 11$ " terhadap beberapa target di New York City dan Washington DC. Pasca serangan 9/11, memicu bertumbuhnya aksi-aksi kekerasan dan terorisme mengatasnamai jihad. Tumbuhnya aksi kekerasan dan terorisme tersebut menyebabkan paham radikalisme Islam semakin menyebar dan mempengaruhi dunia seluruhnya. Radikalisme Islam ini sebetulnya bukan hanya sebatas gerakan ekstrim dengan cara kekerasan dan teror, tetapi juga sebuah realitas kompleks yang bersinggungan dengan persoalan politik, ekonomi dan budaya dan sangat berdampak pada sistem demokrasi modern serta berbenturan dengan pluralisme dan multikulturalisme. Mengapa demikian? Sebab, radikalisme Islam itu sekurangkurangnya memiliki dua ciri: pertama, penggunaan kekerasan sebagai sarana mencapai tujuan; kedua, perlunya perubahan pada ideologi dan sistem sekular dan menggantikannya dengan ideologi dan sistem islami. ${ }^{4}$

Radikalisme Islam ini erat kaitannya dengan islamisme. Paham islamisme yang mendefiniskan Islam sebagai ideologi politik ini dicetus oleh dua ideolog besar, pertama: Hasan al-Banna (1906-1949) yang mendirikan al-Ikhwan al-Muslimun (Persaudaraan Muslim) tahun 1928 dengan tujuan merevitalisasi segala hal yang diyakini sebagai iman Islam yang sudah bobrok, dengan jalan menyediakan suara politik bagi orang beriman, yakni sebuah partai Islam. Kedua, Abul Ala Maudidi (1903-1978), penggagas partai jemaat islami di Indo-Pakistan. Al-Ikhwan al-Muslimun dan jemaat islami ini berkembang dengan sangat cepat di Kawasan Timur Tengah. AlIkhwan al-Muslimun misalnya, disebutkan melahirkan beberapa kelompok radikal antara lain: Hizbut Tahrir, jihad Islam, jama'ah islamiyah, dan jama 'ah al-Takfir serta beberapa kelompok islamis lainnya seperti Hamas di Palestina, Hisbulah di Libanon,

\footnotetext{
${ }^{3}$ Vedi R. Hadiz, Islamic Populism in Indonesia and the Middle East (Cambridge: Cambridge University Press, 2016), 14.

${ }^{4}$ Noorhaidi Hasan, "Mendiskusikan Radikalisme Islam: Definisi dan Strategi Wacana, dalam Masjid dan Pembangunan Perdamaian (Jakarta: CSRC UIN Syarif Hidayatullah, 2011), 47.
} 
FIS (Front Islamique Du Salut) di Aljazair dan Gerakan Salafi di Arab Saudi. ${ }^{5}$ Gerakan-gerakan kelompok islamisme ini memiliki karakteristik politik yang berbasiskan agama. Hisbut Tahrir misalnya, menjadikan sistem kekhalifahan sebagai inti perjuangannya. Kelompok ini meyakini bahwa dengan sistem kekhalifahan umat Islam menunjukkan solidaritasnya melawan agresi-agresi westernisasi dan modernitas yang telah merusak tatanan keislaman yang sesungguhnya.

Fakta adanya berbagai kelompok islamisme yang berkembang ini, Olivier Roy kemudian membedakannya atas dua yakni, islamisme radikal dan islamisme moderat. Islamisme moderat adalah kelompok yang mengupayakan proyek reislamisasi dari bawah dengan jalan berdakwah. Kelompok ini juga bernegosiasi dan melakukan aliansi politik untuk mendorong islamisasi dengan memberlakukan syariat Islam melalui legislasi. Sedangkan islamisme radikal menekankan pentingnya cara-cara nonkompromi bahkan dengan cara revolusi demi pembentukan negara Islam. Roy berkesimpulan, jika islamisme moderat membela posisi Islam dalam politik yang reformis, maka islamisme radikal lebih mengutamakan jalan revolusi untuk menerapkan ideologi Islam menggantikan ideologi yang sedang berkuasa. ${ }^{6}$

Lain lagi pengklasifikasian yang dibuat oleh International Crisis Group (ICG) yang menyamakan islamisme dengan istilah "aktivisme Islam" yang berarti gencar melakukan gerakan yang bercorak islamis. Untuk memahami arus utama islamisme ini, menurut ICG titik masuknya harus membedakan antara Islamisme Sunni dan Islamisme Syi'ah. Islamisme Syi'ah ini tergolong minoritas dan lebih memperjuangkan kepentingan Syi'ah, sehingga tak terfragmentasi ke dalam bentukbentuk aktivisme yang saling bersaing seperti Islamisme Sunni. Sedangkan aktivisme Islamisme Sunni dapat dikategorikan ke dalam tiga arus utama ini: pertama, islamisme politik yang bertujuan untuk meraih kekuasaan politik, seperti di Mesir dengan gerakan Ikhwanul Muslimin, juga di negara-negara lain seperti Aljaziar, Jordania, Kuwait, Palestina, Sudan dan Maroko. Kedua, islamisme dakhwahis. Kelompok ini tidak terlibat dalam aktivitas politik. Fokusnya tertuju pada gerakan dakwah, seperti yang diwakili oleh gerakan Jema'ah Tabligh (JT) dan gerakan salafi. ${ }^{7}$ Selanjutnya, kategori ketiga adalah islamisme jihadis. Kelompok ini memiliki ciri utama penggunaan kekerasan untuk memperjuangkan nilai-nilai yang diyakini. ${ }^{8}$

Fakta radikalisme Islam melalui berbagai corak gerakan islamis menyebar dengan begitu cepat di dunia Muslim dan menjadi obyek yang sangat mengkhwatirkan dunia seluruhnya, termasuk di Indonesia. Fakta ini menjadi fokus kajian dalam berbagai geliat akademis dan menjadi bahan diskusi yang tetap aktual. Indonesia

\footnotetext{
${ }^{5}$ Ibid., 48-49.

${ }^{6}$ Amelia Fauzia dan kawan-kawan, Islam di Ruang Publik. Politik Identitas dan Masa Depan Demokrasi di Indonesia (Jakarta: CSRC UIN Syarif Hidayatullah, 2011), 14-15.

${ }^{7}$ Gerakan Jemaah Tablig ini didirikan di India tahun 1926 dan menggiatkan kampanye dakwah dengan melakukan khuruj, artinya: keluar berdakwah di jalan Allah minimal sekali bagi anggota Jemaah. Sedangkan gerakan salafi ini berusaha merestorasi Islam dengan membersihkannya dari pengaruh-pengaruh bidaah dan pembaruan-pembaruan modern. Kelompok ini berusaha menonjolkan identitas eksklusif mereka yakni berbusana jalabiyya (jubah dan gamis), berjenggot, bercelana cingkrang, memakai sorban dan bagi wanita wajib bercadar. Lihat, Amelia Fauzia dan kawan-kawan, Islam di Ruang Publik, 17-18.

${ }^{8}$ Ibid., 16-19.
} 
sebagai salah satu negara Muslim terbesar di dunia, tentunya memiliki dinamika kontestasi tersendiri menyikapi fenomena radikalisme Islam yang nampak dalam gerakan-gerakan islamisme tersebut.

\section{b. Konteks Indonesia}

Radikalisme Islam yang berhubungan erat dengan islamisme sebetulnya sudah muncul di Indonesia beberapa waktu sebelumnya. Sejarah umat Islam Indonesia pernah melahirkan ideologi bercorak islamis yakni: pertama, pembentukan negara Islam Indonesia (NII) di Jawa Barat, Sulawesi dan Aceh. Kedua, ideologi Islam sebagai dasar negara seperti pada pengusulan tujuh kata dalam konstituante: "dengan menjalankan syariat Islam bagi para pemeluknya". Ketiga, konsep penerapan hukum Islam dalam hidup pribadi, bermasyarakat dan bernegara seperti yang diperjuangkan sejak awal oleh kelompok masyumi. Ketiga ideologi islamis ini memang sempat mencuat di permukaan namun berhasil digagalkan.

Fenomena islamis ini kembali tampil pada akhir tahun 1980-an masa pemerintahan Orde Baru yang mulai menerapkan kebijakan mengakomodasi politik Islam. Kebijakan tersebut antara lain melalui pembentukan Ikatan Cendikiawan Muslim Indonesia (ICMI) untuk mengakomodir kepentingan Islam dalam kebijakan nasional. Pada era inilah simbol-simbol identitas keislaman mulai kelihatan walau masih sangat terbatas. Baru pada era reformasi, dengan dalil kebebasan, otonomi dan hak azasi manusia, munculah gerakan-gerakan islamisme. ${ }^{9}$

Gerakan islamisme yang bangkit pasca lengsernya Orde Baru dibagi dalam dua model gerakan. Model pertama ditandai dengan maraknya pendirian partai-partai bercorak islamis, seperti Partai Bulan Bintang (PBB), Partai Keadilan Sosial (PKS), Partai Kebangkitan Umat (PKU), Partai Masyumi Baru dan Partai Persatuan. Model gerakan kedua ditandai dengan munculnya ormas-ormas Islam yang dapat diklasifikasi menurut ketentuan ICG yakni: pertama, islamis politik, seperti Partai Keadilan Sosial (PKS), Hizb al-Tahrir Indonesia (HTI), dan Majelis Mujahidin Indonesia (MMI). Kedua, islamis dakwahis, seperti Jemaat Tablig (JT) yang melakukan kampanye dakwah untuk untuk hidup di jalan Allah, meninggalkan dunia politik, promosi jilbabisasi serta membatasi interaksi sosial dengan non-muslim. Termasuk kelompok ini adalah gerakan salafiyah yang ingin mengembalikan umat kepada Islam murni yang belum tercemar oleh tradisi lokal dan wacana doktrinal tertentu. Ciri utama kelompok salafi ini adalah kaum wanita bercadar dan kaum pria berjenggot, berjubah dan bercelana cingkrang. Ada juga kelompok lain namun lebih bercorak dakwahis jihadis yaitu Front Pembela Islam (FPI), yang sering menggunakan kekerasan di atas slogan, "amar ma'ruf, nahyi munkar" (melakukan yang baik dan menghindari yang jahat). Ketiga, islamis jihadis, seperti Jema'ah Islamiyah dan dimasukkan juga Majelis Mujahidin Indonesia (MMI). ${ }^{10}$ Gerakan-gerakan islamisme ini kemudian berbarengan dengan konflik-konflik komunal antar agama tingkat lokal (Ambon, Poso, Ternate,

\footnotetext{
${ }^{9}$ Achmad Jainuri dan kawan-kawan, Terorisme dan Fundamentalisme Agama. Sebuah Tafsir Sosial (Malang: Bayu Media, 2003), 217-218.

${ }^{10}$ Amelia Fauzia dan kawan-kawan, Islam di Ruang Publik, 16-19.
} 
Jayapura) dengan seruan jihad, menjamurnya perda-perda syariat di beberapa daerah, pembakaran Gereja, pelarangan mendirikan Gereja, serta aksi terorisme di beberapa tempat dan daerah yang masih terus berlangsung sampai saat ini.

Fakta adanya gerakan islamisme terkini dan sangat penting adalah aksi gerakan massa bela agama atau dikenal dengan "Aksi Bela Islam" dalam nyala api demonstrasi "411, 212 di Jakarta akhir tahun 2016 sampai awal Januari 2017. Aksi bela Islam ini terus berlanjut selama masa menjelang Pilkada DKI tahun 2017 yang melibatkan pertarungan antara pasangan petahana Basuki Tjahaya Purnama dan Djarot Saiful Hidayar (Ahok-Djarot) bersaing dengan pasangan Anies Baswedan dan Sandiaga Uno (Anis-Sandhi). Selama masa pilkada ini issu agama menjadi sangat "panas" dan begitu meluas. Ciri-ciri islamisme sangat nampak, misalnya jika ada warga pendukung AhokDjarot meninggal dilarang disholatkan di Masjid. Issu agama ini diperankan oleh kelompok islamis yang ditengarai berada di kubu Anies-Sandhi. Akhir Pilkada DKI Jakarta dimenangkan oleh Anis-Sandhi dan berbuntut dengan dipenjarainya Ahok atas tuduhan penistaan agama (Islam). Pergolakan politik Pilkada DKI Jakarta yang sarat dengan issu agama yang dipolitisir membuat Vedi R. Hadiz melakukan kajian dengan bertolak dari pertanyaan mendasar yakni: apakah peristiwa "Aksi Bela Islam" ini menandakan titik awal kebangkitan populisme Islam baru di Indonesia?" ${ }^{11}$ Hadiz berpendapat bahwa, populisme Islam baru tersebut adalah bentuk spesifik dari mobilisasi sosial berbasis koalisi multikelas yang asimetris, yang berusaha untuk memperjuangkan agenda politik dan ekonomi namun kurang berpijak pada doktrin agama atau norma budaya yang sesungguhnya. Meskipun gerakan ini didorong oleh penafsiran atas doktrin agama dan budaya. Dengan berdalih untuk memperjuangkan nilai-nilai dan cita-cita umat, agenda kelompok ini terus diperjuangkan dengan gaya imperatif sambil berjejaring dengan kepentingan dan kekuasan sosial-politik. ${ }^{12}$

Populisme Islam tidak hanya nampak dalam aksi show power ribuan Muslim yang turun ke jalan, tetapi gerakan-gerakan intrinsiknya yang bernegosiasi dengan partai-partai dan ormas-ormas bercorak islamis-radikal lainnya serta dukungan elit politik, sedang berkolaborasi untuk membawa pengaruh bagi kebijakan politik dan sosial yang bisa saja berdampak pada kemerosotan mutu demokrasi di Indonesia. Sebab, islamisme saat ini merupakan salah satu gerakan politik yang sedang berkontestasi dengan demokrasi di Indonesia. Demokrasi Indonesia sedang berada dalam pusaran arus islamisme, yang menghendaki negara khilafah berbasiskan syariat Islam. Meski kekuatan mayoritas Islam kultural (NU dan Muhammadiyah) masih sangat solid pada Pancasila dan UUD 1945, dengan semboyan Bhinneka Tunggal Ika dan semangat "NKRI harga mati", ciri-ciri islamisme dengan berbagai aksinya termasuk populisme Islam baru tersebut, merupakan fenomena yang harus disikapi serius oleh segenap komponen bangsa: pemimpin dan rakyat se-antero Nusantara ini.

${ }^{11}$ Vedi R. Hadiz, Direktur dan Profesor Asian Studies, Asia Institute serta Assistant Deputy Vice Chancellor International, Dalam karyanya yang berjudul: Islamis Populism in Indonesia and the Middle East, ia mengungkapan fakta tentang gerakan populisme Islam di Mesir, Turki dan Indonesia. Lihat Vedi R. Hadiz, Islamic Populism in Indonesia and the Middle East (Cambridge: Cambridge University Press, 2016), 11-12.

12 Vedi R. Hadiz, Islamic Populism in Indonesia and the Middle East, 20. 


\section{Apakah Islamisme Mengancam Demokrasi dan Pluralisme di Indonesia?}

Bassam Tibi, seorang ilmuwan hubungan internasional yang memperkenalkan Islam dengan tema-tema konflik internasional dan peradaban, membuat kategori pembedan antara Islam dan islamisme. Menurutnya, islamisme itu termasuk dalam kategori politik keagamaan dan berbeda dengan Islam. Islamisme tidak berpijak pada keyakinan agama Islam tetapi berasal dari interpretasi politis atas Islam dan oleh Tibi, model ini adalah contoh paling kuat dari fenomena global fundamentalisme agama. ${ }^{13}$ Tibi menolak keras model ini, sebab menurutnya, Islam memang menyiratkan nilainilai politis tertentu namun tidak mensyaratkan suatu tata pemerintahan khusus. Islamisme bukanlah Islam itu sendiri tetapi politik yang diagamaisasikan (religionized politics). ${ }^{14}$

Menurutnya, eksistensi islamisme di era global ini diakibatkan oleh krisis ganda: pertama, bersifat normatif yakni berkaitan dengan kesulitan menghadapi modernitas sekular, dan kedua, bersifat struktural yakni berkaitan dengan kegagalan pembangunan di dunia Arab. Oleh karena itu, menurut islamisme upaya yang harus ditempuh mengatasi krisis ini adalah kembali kepada yang suci. Solusi untuk kembali kepada yang suci ini bukan dalam bentuk "renaisans agama" tetapi dalam konsep agama yang diberi bentuk politis. ${ }^{15}$ Untuk memperkuat argumennya ini, Tibi menyebutkan enam karakter yang menjadi ciri utama islamisme, yakni: nizam islami (negara Islam), ${ }^{16}$ anti Yahudi (Amerika dan barat) ${ }^{17}$ demokratisasi ala islamisme, ${ }^{18}$ jihadisme $^{19}$, ,yariatisasi negara ${ }^{20}$ dan purifikasi. ${ }^{21}$

Keenam ciri utama ideologi islamisme ini merupakan model politik islamis yang mencirikan ideologi totaliter untuk mengimplementasikan al-islami. ${ }^{22}$ Ideologi totaliter ini mengatur semua aspek kehidupan manusia dan tidak menyediakan ruang kosong bagi ruang kebebasan individu serta menuntut kesetiaan total yang sama dalam hidup dan mati, tidak terbatas, tanpa syarat dan tidak dapat diubah. Ideologi ini tidak menganut paham demokrasi yang benar dan hukum syariat pun dipraktekkan secara sewenang-wenang. Strategi yang digunakan adalah pola indoktrinasi yang dikombinasikan dengan teror, perang propaganda, dan perang gagasan (harb alafkar). ${ }^{23}$

Merujuk pada pembedaan Islam dan islamisme menurut Tibi di atas, konteks islamisme Indonesia sebetulnya sudah terpapar juga di antara keenam kriteria yang disebutkan. Meskipun, upaya nizam islami (negara Islam) masih merupakan wacana

\footnotetext{
${ }^{13}$ Bassam Tibi, Islamisme and Islam (New Heaven-London: Yale University Press, 2012), 1.

${ }^{14}$ Ibid.

15 Ibid., 1-2.

${ }^{16}$ Ibid., 31.

${ }^{17}$ Ibid., 54

18 Ibid., 94.

19 Ibid., 134.

${ }^{20}$ Ibid., 158.

${ }^{21}$ Ibid., 177.

${ }^{22}$ Ibid., 202.

${ }^{23}$ Ibid., 210-216.
} 
lepas, kelima ciri islamisme lainnya sebetulnya sedang menggerogoti dan telah menyusup masuk dalam dinamika hidup kaum Muslim Indonesia yang diberi label Muslim kultural atau Muslim Nusantara ${ }^{24}$ (menurut terminologi NU). Ideologi dan aksi dari berbagai kelompok islamis yang ada mencirikan kriteria-kriteria islamisme seperti yang diutarakan Tibi, antara lain mempersoalkan nilai-nilai demokratis pluralisme, melegitimasi kekerasan, upaya pemberlakuan hukum syariat, serta penerapan purifikasi yang rigid dan ketat. Semua ciri ini bersifat politis yang diberi label agama, sehingga menjadi politik yang diagamaisasikan. Itulah inti islamisme.

Lalu bagaiamana tendensinya bagi demokrasi Indonesia berhadapan dengan ciri-ciri islamisme yang sudah merayap masuk dalam bingkai keindonesiaan yang pluralistis ini? Center for the Study of Religion and Culture (CSRC) Universitas Islam Negeri Syarif Hidyatullah Jakarta (CSRC UIN Jakarta) pada tahun 2010 melakukan riset di 10 propinsi dengan tajuk "Islamisasi di Ruang Publik. Identitas Muslim dan Menegosiasikan Masa Depan Demokrasi di Indonesia". Riset ini membuat survey tentang fenomena Islam di ruang publik, apakah berorientasi islamisme atau Islam kultural? Proses analisisnya menggunakan analisis Cluster atas tiga indikator, pertama: kewajiban menggunakan cadar, kedua: penegakkan negara Islam Indonesia, ketiga: bolehnya menggunakan cara-cara kekerasan dalam memperjuangkan Islam. Hasil analisis menunjukkan bahwa jumlah Muslim yang memiliki orientasi islamisme sebesar 19,9\%, sementara mayoritas masyarakat Muslim lainnya sebesar 80,1\%, dan kecenderungan Islamnya adalah Islam kultural. ${ }^{25}$

Dari sisi angka, jumlah 19,9 \% masyarakat Muslim yang berorientasi islamisme bukanlah angka kecil. Karena itu berarti dua dari sepuluh orang Indonesia memiliki kecenderungan islamisme yang potensial untuk diindoktrinasi benih-benih islamisme jihadis. Hal ini harus dianggap sebagai ancaman bagi mayoritas Muslim kultural Indonesia. Temuan angka ini berarti kecenderungan islamisme di Indonesia mengalami peningkatan. ${ }^{26}$ Meskipun begitu, riset ini juga menyebutkan bahwa hanya ada $5 \%$ kelompok islamisme yang betul-betul terlibat aktif dalam aksi-aksi kelompok islamisme. Sebuah angka yang relatif kecil. ${ }^{27}$ Dalam riset ini juga ditegaskan bahwa meskipun kecenderungan islamisme mengalami peningkatan, 87,1\% Muslim menyatakan persetujuannya dengan sistem demokrasi yang sedang berlangsung saat ini dan cuma $12,9 \%$ yang menolak demokrasi saat ini. ${ }^{28}$ Itu berarti, gerakan islamisme saat itu (10 tahun lalu) belum mengancam sistem berdemokrasi di Indonesia. ${ }^{29}$

Lalu apa yang terjadi dengan demokrasi Indonesia setelah satu dekade penelitian CSRC UIN Jakarta tersebut? Menyimak kajian dari Vedi R. Hadiz, demokrasi Indonesia saat ini berhadapan dengan gerakan islamic populism yang

${ }^{24}$ Istilah "Islam Nusantara" adalah Islam yang memiliki karakter dan bercorak Nusantara yang mengakomodasi tradisi-tradisi dan alam pikiran orang Nusantara, dengan tetap dan berangkat dari titik pijak Islam. Lihat, Jamaah Nahdliyin Mataran (JNM), Gerakan Kultural Islam Nusantara (Jogyakarta: JNM dan Panitia Muktamar NU ke 33, 2015),4.

${ }^{25}$ Amelia Fauzia dan kawan-kawan, Islam di Ruang Publik, 59-60.

${ }^{26}$ Ibid., 149

${ }^{27}$ Ibid., 149-150.

${ }^{28}$ Ibid., 64-65

${ }^{29}$ Ibid., 150. 
tergabung dari berbagai komponen partai dan ormas bernuansa islamis. Menurutnya, populisme Islam baru, baik dalam model gerakan partai (PKS misalnya), maupun dalam gerakan ormas (FPI dan lainnya), ketika terlibat dalam konteks berdemokrasi ala Indonesia, justru mengalami pergeseran ideologis yang penting. Mengapa? Pergeseran ideologis ini terjadi karena adanya kebutuhan untuk bertahan hidup dalam proses demokrasi Indonesia meskipun harus digerakan oleh politik uang dan sering kacau balau, bukan karena adanya keharusan doktrin religius.$^{30} \mathrm{PKS}$ sendiri misalnya, telah membangun argument bahwa "menerapkan syariat secara kaku dan harafiah tidaklah wajib". Dengan mengambil sikap seperti ini, PKS jelas telah mengambil kontingensi politik Indonesia yang demokratis. Sebab, membuat aliansi yang didasarkan pada kemurnian ideologis, untuk sementara sulit untuk diterapkan di Indonesia. ${ }^{31}$ Demikianpun dengan FPI, yang secara ideologis menentang politik demokrasi sebab dianggap bercorak islamis atas dasar doktrin agama, malah semakin jauh terbawa dan terlibat ke dalam politik elektoral, sebagaimana yang ditunjukkan dengan mendukung calon Presiden Prabowo Subianto pada pemilihan presiden yang lalu. Sebab, jika FPI tidak terlibat dalam politik elektorial, resikonya ormas ini akan terpinggirkan dari ketertarikan massa Muslim. ${ }^{32}$ Jadi, FPI pun mengalami perubahan haluan ideologis. Sementara itu, HTI sendiri sebuah organisasi antidemokrasi yang mengadvokasi kekhalifahan global, justru membuat ormas ini tidak banyak fokus pada perjuangan berbasis nasional. Rivitalisasi khilafah yang bertentangan dengan Pancasila serta tidak berkonsentrasi dan berkontribusi pada politik berbasisi nasional, akhirnya membuat pemerintah Indonesia membubarkan HTI ini pada tanggal 19 Juli 2017, dengan mencabut status badan hukum ormas tersebut. ${ }^{33}$

Sistem dan konteks berdemokrasi di Indonesia ternyata telah memoderatkan politik gerakan islamis Indonesia. Berdasarkan fakta gerakan islamis, Hadiz lalu menegaskan bahwa populisme Islam baru di Indonesia ketika berhadapan dengan demokrasi Indonesia yang didominasi politik uang, malah memperparah fragmentasi di kalangan internal ormas-ormas tersebut. Sehingga, sulit bagi populisme Islam baru itu sukses mencapai ranah demokrasi tanpa ada basis sosial yang cukup luas sekaligus kendaraan politik yang koheren yang dapat mengunci kesetiaan umat Muslim yang secara sosiologis beragam. ${ }^{34} \mathrm{Jadi}$, populisme Islam baru di Indonesia masih sedang berkembang dan belum menjadi suatu kekuatan sosial yang otonom yang dapat mendominasi civil society dan negara. Populisme Islam baru ini sedang dalam tahap pemosisian ulang yang menguntungkan umat Islam yang terpinggirkan, namun masih dalam batas negara-bangsa, melalui serangkaian kontestasi yang memungkinkan, dan belum sampai pada tahapan untuk mendirikan negara Islam berbasiskan syariat. ${ }^{35}$

Setelah Riset dari Fauzia dan kawan-kawan dibuat 10 tahun lalu dan fenomena populisme Islam baru yang gagal mengancam demokrasi di Indonesia, lantas apakah

\footnotetext{
${ }^{30}$ Vedi R. Hadiz, Islamic Populism in Indonesia and the Middle East, 140

${ }^{31}$ Ibid., 148-149.

${ }^{32}$ Ibid., 186.

${ }^{33}$ Kompas Online, $\quad$ https://nasional.kompas.com/read/2017/07/19/10180761/hti-resmidibubarkan-pemerintah?page=all, diakses 28 Januari 2020.

${ }^{34}$ Vedi R. Hadiz, Islamic Populism in Indonesia and the Middle East, 158.

${ }^{35}$ Ibid., 4.
} 
islamisme dengan berbagai sepak terjang dan srateginya juga dikatakan gagal? Dalam konteks berdemokrasi memang gagal, namun bahaya dan ancaman laten islamisme tetap menjadi tugas bersama untuk merawat bangsa ini. Simak saja beberapa perstiwa intoleren yang terjadi dalam 2-3 tahun belakangan ini. Meskipun bersifat sporadis namun menarik diangkat dan dicermati dalam konteks pergerakan islamisme di Indonesia. Rektor UIN Sunan Kalijaga, dua tahun lalu mengeluarkan SK pendataan mahasiswa bercadar di kampusnya. Setelah mendata 41 mahasiswi yang menggunakan cadar, dilakukan sosialisasi dan konseling pada 5 Maret 2018. Pihak kampus mengancam akan mengeluarkan mahasiswa jika sudah tujuh kali diperingatkan dan dibina, tetap saja memakai cadar. ${ }^{36}$ Meskipun SK tersebut akhirnya dicabut pada tanggal 10 Maret 2018, oleh karena berbagai tekanan pro-kontra, kebijakan yang dilakukan Rektor UIN Yogyakarta tersebut adalah bagian dari pembinaan lingkungan kampus yang kondusif, agar terhindar dari pengaruh dan ideologi islamis-radikal. ${ }^{37}$ Sementara itu, Menteri Agama Kabinet Indonesia Maju, Fachrul Razi, beberapa waktu setelah pelantikan langsung mengeluarkan banyak pernyataan soal larangan bercadar dan bercelana cingkrang bagi Aparatur Sipil Negara (ASN). Menteri Agama tetap bersikukuh untuk menerapkan kebijakan melarang mengenakan cadar dan bercelana cingkrang bagi ASN serta meneribitkan sertifikat bagi penceramah di tempat ibadat. ${ }^{38}$ Peristiwa lainnya adalah tindakan-tindakan intoleran seperti: penyerangan tokoh agama non-muslim, pemotongan salib, penolakan keluarga non-Muslim di wilayah Muslim, yang terjadi beberapa waktu lalu.

Contoh-contoh yang disebutkan di atas, meskipun banyak menimbulkan pro dan kontra, fenomena tersebut tetap mengindikasikan adanya penguatan gerakan islamisme di Indonesia. Meskipun belum mengerucut pada kehendak mendirikan negara Islam berbasis syariat, namun terobsesi oleh klaim kebenaran otentik menurut agama, kalangan islamis sedang membenarkan politik pemurnian islamisme dengan upaya untuk kembali pada yang suci serta menghapus semua hal apa saja yang "inauthentic". Model pemahaman yang demikian menurut Tibi adalah sebuah bentuk politik identitas islamis yang justru berfungsi sebagai polarisasi yang dapat menimbulkan perpecahan dan bukan sebagai sarana penghubung yang mendamaikan satu sama lain. ${ }^{39}$ Politik identitas yang demikian telah menyangkal pluralisme agama dan budaya. Jadi, bagaimana pun, islamisme tetap harus diwaspadai sebab mengancam pluralisme dan demokrasi.

\section{Evaluasi Kritis Menyikapi Gerakan Islamisme di Indonesia}

Gerakan islamisme di Indonesia merupakan salah satu bentuk radikalisme Islam yang terus-menerus menonjol di ruang publik. Meskipun islamisme Indonesia belum

36 Tempo Online, https://nasional.tempo.co/read/1066740/uin-sunan-kalijaga-yogya-larangmahasiswi-bercadar/full\&view=ok, diakses 28 Januari 2020.

37 CNN Indonesia, https://www.cnnindonesia.com/nasional/20180310214806-20282037/rektor-uin-yogyakarta-cabut-larangan-bercadar-di-kampus., diakses 28 Januari 2020.

${ }^{38}$ BBC Com, https://www.bbc.com/indonesia/indonesia-51145161, diakses 28 Januari 2020.

${ }^{39}$ Bassam Tibi, Islamisme and Islam, 40. 
sungguh mengancam demokrasi dan belum menjadi kekuatan otonom yang dapat mendominasi civil society dan negara, pergerakan islamisme perlu diberi catatan kritis:

a. Pertama, klaim kebenaran otentik menurut agama demi politik pemurnian islamisme dengan menghapus semua yang inauthentic, perlu dikritisi. Penulis menggunakan paradigma berpikir dari Jürgen Habermas untuk mengkritisinya. Menurut Habermas, konten kebenaran agama tertentu yang masuk ke ruang publik harus diterjemahkan dari kosa kata komunitas agama tertentu ke dalam bahasa yang dapat diakses secara umum. ${ }^{40}$ Selanjutnya, untuk mengatasi konflik antara pandangan dunia dan doktrin agama, Habermas mengembangkan gagasan tentang "modernisasi kesadaran religius" sebagai respons terhadap tantangan yang dihadapi tradisi keagamaan akibat adanya fakta pluralisme, sains modern, penyebaran hukum positif dan moralitas profan. ${ }^{41}$ Berhadapan dengan situasi ini, Habermas menghendaki agar warga negara yang beragama harus mengembangkan sikap epistemik dalam tiga hal ini: pertama, menghubungkan kepercayaan agamanya dengan doktrin keselamatan yang saling bersaing sedemikian rupa sehingga tak ada klaim kebenaran eksklusif; kedua, memahami hubungan antara kepercayaan dogmatis dan dunia sekular sehingga kemajuan otonomi dalam pengetahuan sekular tidak bertentangan dengan iman agamanya; ketiga, menghubungkan individualisme egaliter dan universalisme hukum modern dan moralitas dengan premis doktrin komprehensif agamanya. ${ }^{42} \mathrm{Jadi}$, klaim kebenaran otentik menurut agama bertentangan dengan spirit "modernisasi kesadaran religius" ketika harus berada di tengah-tengah fakta pluralisme, seperti di Indonesia.

b. Kedua, dalam konteks kebhinekaan Indonesia, model islamisme yang sedang merayap masuk ke dalam kehidupan kaum Muslim saat ini, menurut Bassam Tibi justru bertentangan dengan rasionalisme dan humanisme Islam. ${ }^{43}$ Penerapan konsep pemurnian yang ketat akan membuat kaum Muslim kesulitan berhadapan dengan modernitas kultural, tertinggal oleh kemajuan sains barat dan standar-standar peradaban yang sudah pernah ada sebelumnya. ${ }^{44}$ Bertolak dari alasan ini, menurut Tibi, islamisme bukanlah alternatif bagi masyarakat sipil karena islamisme menolak nilai-nilai inti yang seharusnya dimiliki oleh semua masyarakat sipil seperti, demokrasi, modernitas dan budaya warga. ${ }^{45}$ Oleh karena itu, gerakan-gerakan yang bercorak islamis itu perlu dikritisi dan menerapkan model civil Islam (Islam sipil) sebagai solusi alternatif menghadapi ideologi islamisme yang sudah dan terus menyusup masuk di kalangan Muslim kultural Indonesia ini. Sebab, civil Islam memiliki tradisi humanisme Islam yang lebih memilih rasionalisme dari pada politik yang diagamaisasikan. ${ }^{46}$ Model civil Islam yang dianjurkan Tibi ini ingin mengembalikan citra Islam

40 Jürgen Habermas, "Religion in the Public Sphere", dalam European Jurnal of Philosophy, $14: 1,10$.

${ }^{41}$ Ibid., 13

${ }^{42}$ Ibid., 13-14.

${ }^{43}$ Bassam Tibi, Islamisme and Islam, 237.

${ }^{44}$ Ibid, 192.

45 Ibid., 231.

${ }^{46}$ Ibid., 238-239. 
yang sesungguhnya dalam konsep rahmatan lil alamin (rahmat untuk semua alam semesta). Sebab, radikalisme Islam melalui gerakan-gerakan islamis tersebut cenderung harafiah dalam memahami ajaran agama atau teks alQur'an. Ditambah lagi dengan sikap teguh tanpa kenal kompromi dalam memegang kebenaran yang diyakini serta watak yang kadang emosional dalam menyikapi keberagaman di Indonesia ini.

\section{Penutup}

Radikalisme Islam dalam aneka gerakan islamis bukanlah momok yang ditakuti meskipun kadang mencengangkan. Dalam bingkai keindonesiaan, model dan berdemokrasi yang terjadi saat ini, sudah menjadi "senjata" yang ampuh untuk menangkal radikalisme Islam melalui gerakan-gerakan islamisnya. Berdasarkan fakta yang diuraikan di atas, radikalisme Islam di Indonesia ternyata belum menjadi kekuatan otonom, yang mampu mendominasi civil society serta Negara Kesatuan Republik Indonesia ini. Meski demikian, bahaya radikalisme Islam tetap harus diwaspadai. Demi memantapkan demokrasi Pancasila, sebagai senjata pamungkas radikalisme Islam, maka etika berdemokrasi yang telah menyimpang secepatnya dibenahi. Politik uang, KKN, serta praktek-praktek nondemokratis lainnya, tetap bisa menjadi faktor pemicu radikalisme itu berkembang. Sebab, ciri utama radikalisme ini berawal dari sikap penolakan dan perlawanan terhadap sistem politik atau rezim yang otoriter dan tak beretika dan ingin menggantikannya dengan nizam islami (sistem Islam). Sambil terus membenahi etika berdemokrasi di Indonesia, bagi kaum muslim seyogyanya tidak berilusi dalam khayalan negara Islam yang agak mustahil terjadi di Indonesia. Mari membangun Islam Indonesia menuju humanitarianisme Islam sipil (civil Islam) yang lebih terintegrasi dengan konteks kebhinekaan Indonesia.

\section{Daftar Kepustakaan}

\section{Ensiklopedia}

Seligman, Edwin R.A. Encyclopedia of the Social Sacience, Vol. XIII-XIV. New York: The Macmillan Company, 1972.

\section{Buku-buku}

Abdurahman, M. AJi Nugroho, Halimah Palamban, Mukharis, Sutinah, dan kawankawan. Al-Qur'an dan Isu-Isu Kontemporer. Yogyakarta: Elsaq Press, 2011.

Azra, Azyumardi. Transformasi Politik Islam. Radikalisme, Khilafatisme dan Demokrasi. Jakarta: Prenadamedia Group dan PPIM UIN Jakarta, 2016.

Effendi, Bahtiar dan Hendro Prasetyo. Radikalisme Agama. Jakarta: Pusat Pengkajian Islam dan Masyarakat (PPIM) IAIN Jakarta, 1998. 
Habermas, Jürgen. "Religion in the Public Sphere", dalam European Jurnal of Philosophy, 14:1, 10.

Hadirman F. Budi (ed.). Demokrasi dan Sentimentalitas. Yogyakarta: Kanisius, 2018.

Hadiz, Vedi R. Islamic Populism in Indonesia and the Middle Est. Cambridge: Cambridge University Press, 2016.

Hasan, Noorhaidi dan Irfan Abubakar (ed.). Islam di Ruang Publik. Politik Identitas dan Masa Depan Demokrasi di Indonesia. Jakarta: Center For the Study of Religion and Culture UIN Syarif Hidayatullah, 2011.

Hasan, Noorhaidi. "Mendiskusikan Radikalisme Islam: Definisi dan Strategi Wacana". Dalam Masjid dan Pembangunan Perdamaian. Jakarta: CSRC UIN Syarif Hidayatullah, 2011.

Heywood, Andrew. Ideologi Politik. Sebuah Pengantar. Terj. Yudi Santoso. Yogyakarta: Pustaka Pelajar, 2016.

Jainuri, Achmad, Zainudin Maliki, dan Syamsul Arifin. Terorisme dan Fundamentalisme Agama. Sebuah Tafsir Sosial. Malang: Bayu Media, 2003.

Jamaah Nahdliyin Mataran (JNM). Gerakan Kultural Islam Nusantara. Yogyakarta: JNM dan Panitia Muktamar NU ke 33, 2015.

Ranchman, Budhy Munawar. Islam Pluralis. Jakarta: Paramadina, 2001.

Tibi, Bassam. Islamisme and Islam. New Heaven-London: Yale University Press, 2012.

\section{Internet}

BBC.Com. https://www.bbc.com/indonesia/indonesia-51145161 Diakses 28 Januari 2020.

CNN Indonesia. https://www.cnnindonesia.com/nasional/20180310214806-20282037/rektor-uin-yogyakarta-cabut-larangan-bercadar-di-kampus. Diakses 28 Januari 2020.

Kompas Online. https://nasional.kompas.com/read/2017/07/19/10180761/hti-resmidibubarkan-pemerintah?page=all. Diakses 28 Januari 2020.

Tempo Online. https://nasional.tempo.co/read/1066740/uin-sunan-kalijaga-yogyalarang-mahasiswi-bercadar/full\&view=ok. Diakses 28 Januari 2020. 